\title{
Brevibacillus borstelensis and Streptomyces albogriseolus have roles to play in degradation of herbicide, sulfosulfuron
}

\author{
Ridhima Arya $^{1}$ Navnit Kumar Mishra ${ }^{1}$ Anil K. Sharma ${ }^{1}$
}

Received: 1 August 2016/Accepted: 1 November 2016/Published online: 16 November 2016

(C) The Author(s) 2016. This article is published with open access at Springerlink.com

\begin{abstract}
Use of herbicides, in particular sulfosulfuron, at more than recommended doses has raised major concerns about the health hazards for animals and humans. In the present study, isolation of sulfosulfuron-degrading Brevibacillus borstelensis and Streptomyces albogriseolus from the field soils in the northwestern region of India was carried out where the use of sulfosulfuron is predominant, and further assessed for their potential to degrade sulfosulfuron individually and together in a consortium form under lab conditions. Concentration of sulfosulfuron was reduced from 10 to $7.72 \mu \mathrm{g} / \mathrm{ml}$ in $12 \mathrm{~h}$ to $5.13 \mu \mathrm{g} / \mathrm{ml}$ in $20 \mathrm{~h}$ by $B$. borstelensis and the metabolites detected by LCMS-MS were aminopyrimidine and a rearranged amine in 12 and $20 \mathrm{~h}$ of growth. Similarly, S. albogriseolus reduced the concentration of sulfosulfuron from 10 to $6.74 \mu \mathrm{g} / \mathrm{ml}$ in $12 \mathrm{~h}$ to $6.62 \mu \mathrm{g} / \mathrm{ml}$ in $20 \mathrm{~h}$ with aminopyrimidine and a rearranged amine as metabolites. $B$. borstelensis and S. albogriseolus together also reduced the concentration of sulfosulfuron from $10 \mu \mathrm{g} / \mathrm{ml}$ in initial hour to $8.34 \mu \mathrm{g} / \mathrm{ml}$ in $12 \mathrm{~h}$ to $6.66 \mu \mathrm{g} / \mathrm{ml}$ in $20 \mathrm{~h}$. Hence, $B$. borstelensis and $S$. albogriseolus provide a safer, inexpensive and effective way to bio-remediate the harmful and toxic sulfosulfuron from the environment if further explored at a larger field scale in near future.
\end{abstract}

Keywords Sulfosulfuron Brevibacillus borstelensis . Streptomyces albogriseolus · Degradation · Metabolites

Anil K. Sharma

anibiotech18@gmail.com

1 Department of Biotechnology, Maharishi Markandeshwar University, Mullana, (Ambala), Haryana 133207, India

\section{Introduction}

The use of pesticides, herbicides and insecticides in agriculture has been significantly amplified in previous years which led to air, water and soil pollution in different regions of the world (Malik and Singh 1993; Walia et al. 1997; Chhonkar and Malik 2002; Sondhia 2008).

Herbicide-like isoproturon was used initially for controlling weeds in the crop but its use has led to expansion of resistance strains of Phalaris minor (Walia et al. 1997; Malik and Singh 1993). Nowadays, herbicides like clodinafop, sulfosulfuron and fenoxaprop-p-ethyl are being preferred for proficient weed control in wheat crop (Chhonkar and Malik 2002). The use of these herbicides in particular sulfosulfuron at more than recommended doses has raised an alarm about the health hazards for animals and humans because of its residues left in soil and crops following its application. Higher levels of residues have been detected in the surface soil that occurs by irrigation, thus posing a threat to groundwater pollution (Sondhia 2008). Effect of sulfosulfuron on Phalaris minor, along with its carryover effects to rotational crops has been studied previously and sulfosulfuron was found to be effective in controlling the weed but its carryover effects have been observed on maize and sorghum crops with an inhibition of $65-73 \%$ of the biomass (Chhonkar et al. 2006).

Many adverse health effects have been found to be associated with sulfosulfuron toxicity in animals (Arnold et al. 2001). Similarly, in wheat crop, there was significant reduction in yield and kernel number per year due to residual sulfonylurea herbicide (Bahrampor and Ziveh 2013). Sulfosulfuron phytotoxicity has been observed in cucurbits and other plants grown in field soil after the harvest of wheat crop (Walia et al. 2000; Kaur et al. 2010). 
A sensitive and very fast analytical method was developed for simultaneous detection of 16 sulfonylurea herbicides including sulfosulfuron in surface water (Yan et al. 2011). Residues of the sulfosulfuron and their harmful effects are detected in crops including sunflower, canola, bean, soybean, lens, sorghum, pea, sugar beet, corn, barley, and sorghum (Hadizadeh 2010). Leaching potential of sulfosulfuron and its metabolite aminopyrimidine in two different soils under lab conditions was studied and the leachates collected from the sandy clay soil and clay loam soil were shown to have high percentages of residues of sulfosulfuron as well as aminopyrimidine (Loganayagi and Ramesh 2013).

Sulfonylurea herbicides were reported to be very much persistent in the environment. These herbicides were used to control a wide range of annual and perennial narrow and broadleaf weeds. The main pathways for sulfonylurea metabolism in the soil have been reported to be chemical hydrolysis and microbial degradation (Brown 1990; Bossi et al. 1999). A number of cases have been reported for detection of sulfosulfuron in soil, fruits, cereals and vegetables and only a few studies are accessible about the microbes degrading them. Keeping the above facts in view, the present study was designed to isolate and characterize sulfosulfuron degrading microorganisms from the field soils where use of sulfosulfuron has been predominant and further screening of their potential to degrade sulfosulfuron individually and together in a consortium form under laboratory conditions.

\section{Materials and methods}

For isolation, soil samples had been collected from wheat fields of northern regions of India. Upper layer of the leaves and debris were removed and 6 inches deep soil near to the root of wheat cereal plants (rhizosphere part) was collected. Serial dilution method was used for enumeration of total number of microbes and Nutrient Agar was used for the growth of microbes. Microorganisms were selected by enrichment culture technique with sulfosulfuron $(25 \mu \mathrm{g} /$ $\mathrm{ml}$ ) addition to Jensen's medium. The number of microbes was enumerated as colony-forming units $/ \mathrm{ml}$ (CFU/ml). Specific colony characteristics like colour, shape, size, hardness, appearance, texture, pigmentation and diameter were observed. Optimization of strain was done using standard procedures. For selection, the selected colonies were re-plated on agar medium containing sulfosulfuron $(25 \mu \mathrm{g} / \mathrm{ml})$ and further checked for growth. Serial dilutions of the two isolates $\left(10^{-1}, 10^{-2}, 10^{-3}, 10^{-4}\right)$ were spotted onto the media plates containing different concentrations of sulfosulfuron $(25,50$ and $500 \mu \mathrm{g} / \mathrm{ml}$, respectively). Cells were stained according to classical Gram's staining and endospore staining as well.
Further morphological, biochemical and physiological analysis of the two isolates was carried out at Microbial Type Culture Collection, IMTECH, Chandigarh, India. Culture samples were collected at initial time point $(0 \mathrm{~h})$, 12 and $20 \mathrm{~h}$ growth of Brevibacillus borstelensis and Streptomyces albogriseolus grown in Jensen's medium containing sulfosulfuron $(10 \mu \mathrm{g} / \mathrm{ml})$ at $37{ }^{\circ} \mathrm{C}$ under shaking conditions. Assessment of the metabolites/degradation products of sulfosulfuron from the above culture samples was studied by liquid chromatography mass spectrometry (LCMS-MS) and HPLC/MS analysis carried at Punjab Biotechnology Incubator, an NABL-accredited Agri and Food testing lab, SAS Nagar (Mohali), Punjab, India.

Using both the microorganisms together, a microbial consortium was developed. Culture samples were collected at initial 0,12 and $20 \mathrm{~h}$ growth of B. borstelensis and $S$. albogriseolus grown together in Jensen's medium containing sulfosulfuron $(10 \mu \mathrm{g} / \mathrm{ml})$ at $37{ }^{\circ} \mathrm{C}$ under shaking conditions. The culture samples were subjected to analysis at Punjab Biotechnology Incubator, Punjab, India, for LCMS/MS analysis.

\section{Results}

As we know, the remediation of the environment and soil is the need of the hour for removal of unwanted chemical pesticides to protect the environment from their ill effects. The present study was done to investigate some novel microbial species for restoring the environment from the ill effects of sulfosulfuron by degradation or removal of this weedicide. The isolated bacterium $B$. borstelensis was found to grow well in the $\mathrm{pH}$ range of 6-9 and the maximum growth was obtained at $\mathrm{pH}$ 7. B. borstelensis displayed growth in the temperature range of $30-40{ }^{\circ} \mathrm{C}$ and growth optima was observed at $37^{\circ} \mathrm{C}$. Another bacterium S. albogriseolus was observed to grow well in the $\mathrm{pH}$ range 7-9 and maximum growth was obtained at $\mathrm{pH}$ 8. S. albogriseolus displayed growth at temperature conditions ranging from 30 to $40{ }^{\circ} \mathrm{C}$ and maximal growth was observed at $37{ }^{\circ} \mathrm{C}$. Both strains were found to grow well at higher concentration of the pesticide sulfosulfuron, and isolated colonies were obtained at higher dilutions of the strains (Table 1).

Concentration of sulfosulfuron was reduced from 10 to $7.72 \mu \mathrm{g} / \mathrm{ml}$ in $12 \mathrm{~h}$ to $5.13 \mu \mathrm{g} / \mathrm{ml}$ in $20 \mathrm{~h}$ by B. borstelensis (Fig. 1a). Metabolites detected by LCMS-MS studies include aminopyrimidine and a rearranged amine in 12 and $20 \mathrm{~h}$ of the growth (Fig. 1b). Similarly, S. albogriseolus reduced the concentration of sulfosulfuron from 10 to $6.74 \mu \mathrm{g} / \mathrm{ml}$ in $12 \mathrm{~h}$ to $6.62 \mu \mathrm{g} / \mathrm{ml}$ in $20 \mathrm{~h}$ (Fig. 2a). Metabolites aminopyrimidine and a rearranged amine were detected by LCMS-MS in 12 and $20 \mathrm{~h}$ growth (Fig. 2b). 
Table 1 Effect of different concentrations of sulfosulfuron on the growth of Brevibacillus borstelensis and Streptomyces albogriseolus

\begin{tabular}{|c|c|c|c|c|c|c|c|}
\hline \multirow[t]{2}{*}{ Isolate } & \multirow{2}{*}{\multicolumn{2}{|c|}{$\begin{array}{l}\text { Conc. of pesticide-Sulfosulfuron } \\
(\mu \mathrm{g} / \mathrm{ml})\end{array}$}} & Neat & $10^{-1}$ & $10^{-2}$ & $10^{-3}$ & $10^{-4}$ \\
\hline & & & \multicolumn{5}{|c|}{ Growth of Brevibacillus borstelensis (no. of colonies) } \\
\hline \multirow[t]{4}{*}{ Brevibacillus borstelensis } & 25 & & Confluent & Confluent & Confluent & 53 & 29 \\
\hline & 50 & & Confluent & Confluent & 55 & 42 & 26 \\
\hline & 500 & & Confluent & Confluent & 46 & 28 & 20 \\
\hline & $\begin{array}{l}\text { Sulfosulfuron } \\
(\mu \mathrm{g} / \mathrm{ml})\end{array}$ & \multicolumn{6}{|c|}{ Growth of Streptomyces albogriseolus (no. of colonies) } \\
\hline \multirow[t]{3}{*}{ Streptomyces albogriseolus } & 25 & Confluent & \multicolumn{2}{|c|}{ Confluent } & Confluent & 19 & 26 \\
\hline & 50 & Confluent & \multicolumn{2}{|c|}{ Confluent } & Confluent & 23 & 19 \\
\hline & 500 & Confluent & \multicolumn{2}{|c|}{ Confluent } & Confluent & 20 & 15 \\
\hline
\end{tabular}

Fig. 1 a Reduction in sulfosulfuron concentration by Brevibacillus borstelensis. b Sulfosulfuron metabolites detection in 12-h growth sample of Brevibacillus borstelensis

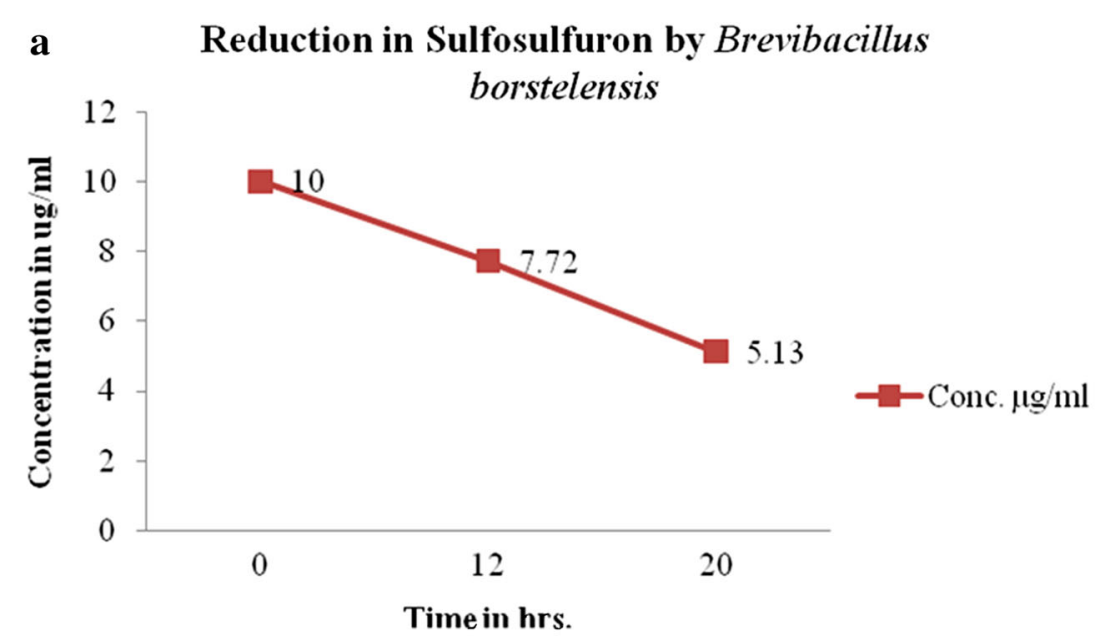

b

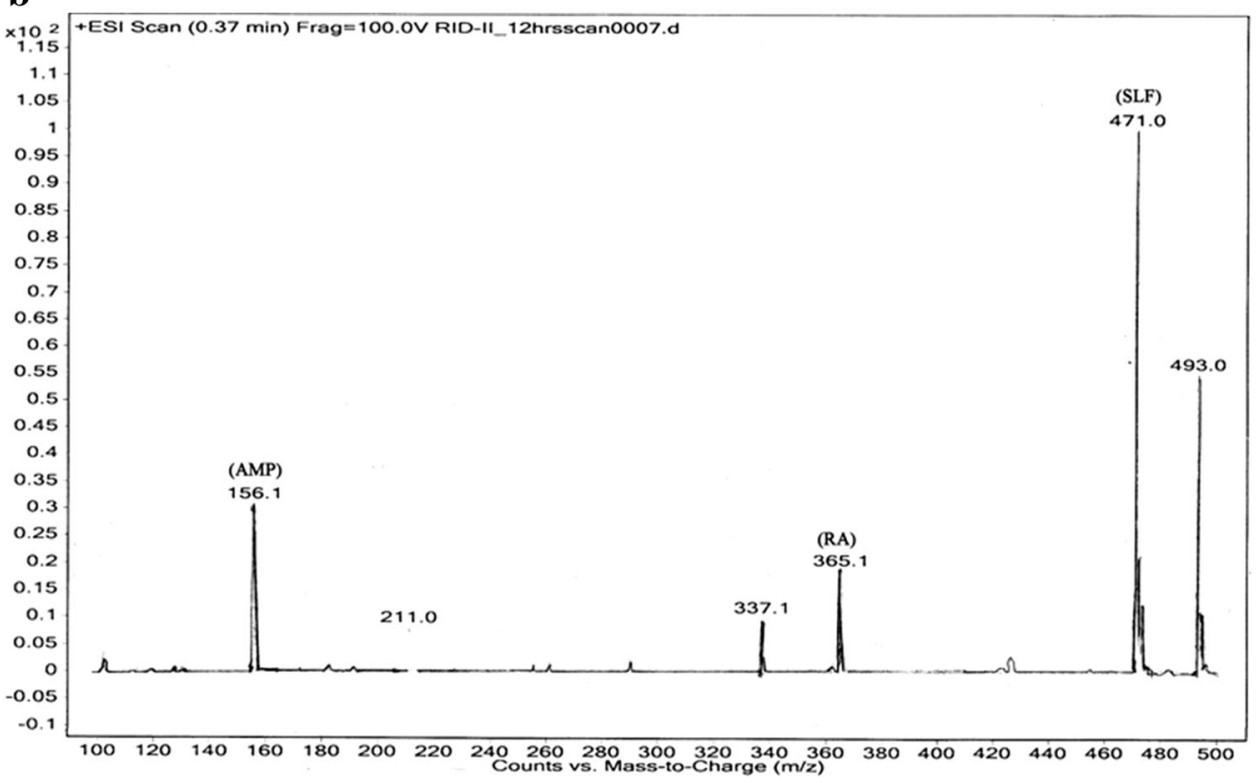


Fig. 2 a Reduction in sulfosulfuron concentration by Streptomyces albogriseolus. b Sulfosulfuron metabolites detection in 12-h growth sample of Streptomyces albogriseolus
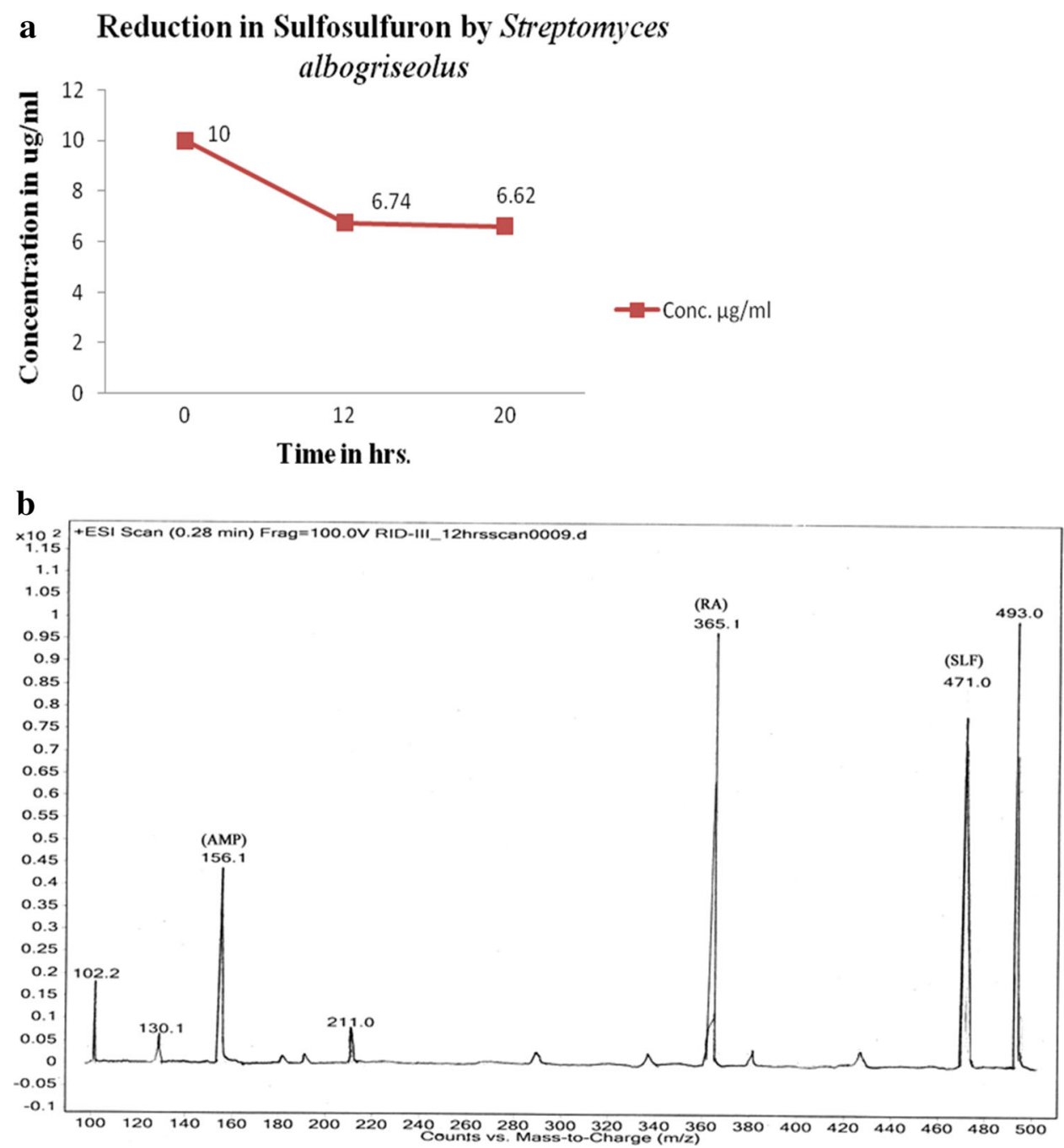

The microbial consortia containing B. borstelensis and $S$. albogriseolus reduced the concentration of sulfosulfuron from $10 \mu \mathrm{g} / \mathrm{ml}$ in initial hour to $8.34 \mu \mathrm{g} / \mathrm{ml}$ in $12 \mathrm{~h}$ to $6.66 \mu \mathrm{g} / \mathrm{ml}$ in $20 \mathrm{~h}$ (Fig. 3a). Metabolites detected by LCMS-MS were aminopyrimidine and a rearranged amine in $12 \mathrm{~h}$ and $20 \mathrm{~h}$ growth of the consortia (Fig. 3b).

Both $B$. borstelensis and $S$. albogriseolus have the capability of successfully degrading sulfosulfuron within 10-20 h of growth. However, degradation was nearly the same in the microbial consortia form. These microbial strains have the ability of degrading sulfosulfuron residues in the soil environment which could be further explored by understanding degradation mechanisms at the genetic level. Efforts may further lead to enhancement of the potential of microorganisms to effectively degrade the pesticides, hence acting as valuable bioremediation agents in near future.

\section{Discussion}

A variety of microorganisms in the soil act as the scavengers of sulfosulfuron (Fig. 4) and is degradation products have been identified as 1-(2-ethylsulfonylimidazo[1,2a]pyridine)-3-(4,6-dimethoxypyramidin-2-yl), 1-(2-ethylsulfonylimidazo [1,2-a]pyridine)-3-sulfonamide and 4,6dimethoxy-2-aminopyramidine (Sondhia and Singhai 2008). Breakdown of pesticides could occur by plants, animals, soil, water and UV radiations, but degradation by microbes, especially fungi and bacteria, is foremostly important (Arya and Sharma 2014a, b, 2015, 2016).

Microbial degradation prevails in neutral to basic soils while in soils with lower $\mathrm{pH}$, the hydrolytic degradation of the compounds is dominant (Menne and Berger 2001; Brar et al. 2006a, b; Sarmah and Sabadie 2002). The photocatalytic degradation of five sulfonylurea herbicides viz. 
Fig. 3 a Reduction in sulfosulfuron concentration by Brevibacillus borstelensis and Streptomyces albogriseolus grown together as consortia. b Sulfosulfuron metabolites detection in 12-h growth sample of consortium containing both isolates Brevibacillus borstelensis and Streptomyces albogriseolus

\section{a Reduction in Sulfosulfuron by Brevibacillus borstelensis and Streptomyces albogriseolus}

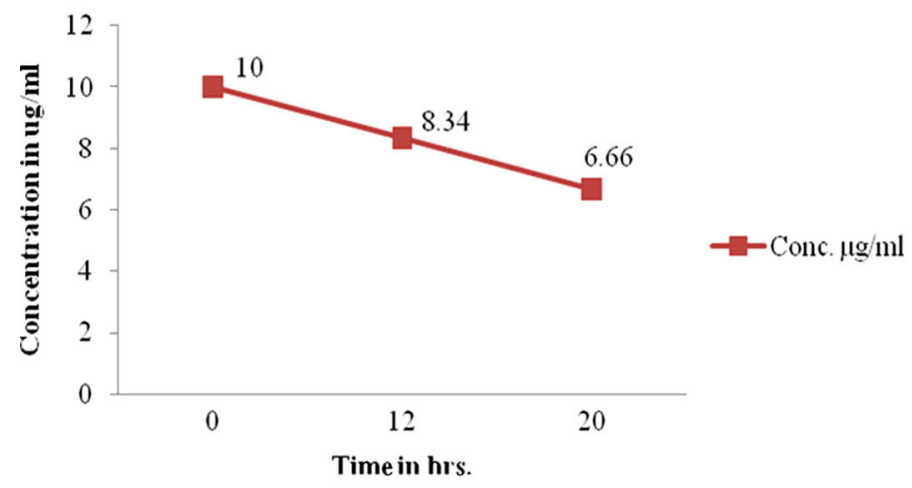

b

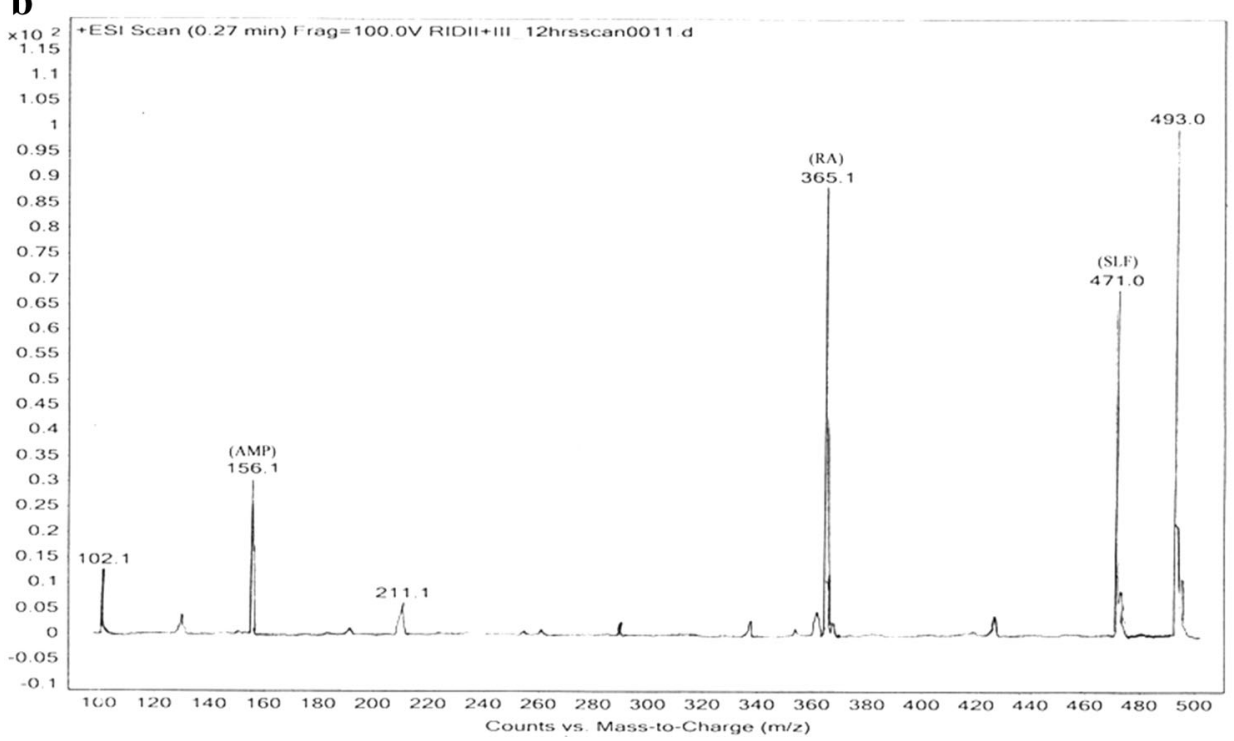

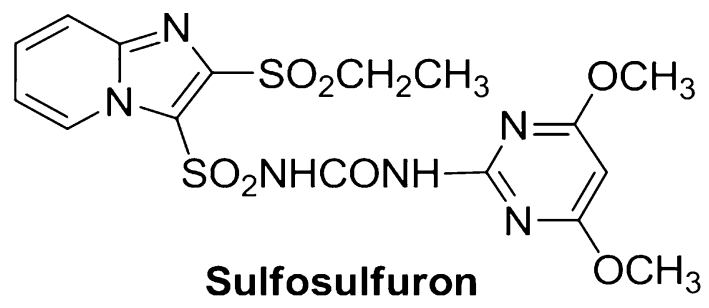

Fig. 4 The IUPAC name of sulfosulfuron is 1-(4, 6-dimethoxypyrimidin-2-yl)-3-(2-ethylsulfonylimidazo [1, 2-a] pyridine-3-ylsulfonyl) urea. The molecular formula of sulfosulfuron is $\mathrm{C}_{16} \mathrm{H}_{18} \mathrm{~N}_{6} \mathrm{O}_{7} \mathrm{~S}_{2}$

chlorosulfuron, nicosulfuron, flazosulfuron, triasulfuron and sulfosulfuron was studied and their degradation followed first order kinetics and none of the pesticides were detected after $120 \mathrm{~min}$ of illumination except chlorosulfuron (Fenoll et al. 2012). Sondhia and Singhai (2008) have shown in their study, the cleavage of the sulfonylurea bridge to form 1-(2-ethylsulfonylimidazo $\left[\begin{array}{ll}1, & 2-\mathrm{a}]\end{array}\right.$ pyridine)-3-sulfonamide and 4, 6-dimethoxy-2-aminopyramidine. Ramesh et al. (2007) through LCMS/MS analysis on water and fish samples, explored the presence of metabolites, ethyl sulfone, aminopyrimidine, desmethyl sulfosulfuron, sulphonamide, guanidine and a rearranged amine.

The stability of sulfosulfuron has been analysed by (Saha and Kulshrestha 2002) in a controlled environment of temperature, $\mathrm{pH}$ and solvent as well its photo-stability after irradiation under sunlight. 1-(2-ethylsulfonylimidazo [1,2a]- pyridin-3-yl-3-(4,6-dimethoxypyrimidin-2-yl) amine as degradation product was observed under alkaline conditions by Saha et al. (2003), and under acidic condition, it degraded to two metabolites, 1-(2-ethylsulfonylimidazo [1,2-a] pyridin)-3-sulfonamide and 4,6-dimethoxy-2-aminopyrimidine by cleavage of sulfonylurea bridge.

Brevibacillus borstelensis as well as S. albogriseolus in our study were found to reduce sulfosulfuron into aminopyrimidine and a rearranged amine due to the 
cleavage or opening of the sulfonylurea bridge of the sulfosulfuron as also discussed elsewhere (Sondhia and Singhai 2008; Saha et al. 2003). Similarly, consortium containing $B$. borstelensis and $S$. albogriseolus grown together reduced sulfosulfuron into aminopyrimidine and a rearranged amine which may have resulted because of the cleavage or opening of the sulfonylurea bridge of the sulfosulfuron (Saha et al. 2003; Saha and Kulshrestha 2002). Both B. borstelensis (Arya and Sharma 2014a, b) and $S$. albogriseolus (Arya et al. 2015) alone and together in consortia form (Arya and Sharma 2016) were also reported previously to degrade a fungicide, carbendazim to 2-aminobenzimidazole, 2-hydroxy benzimidazole and benzimidazole as well.

\section{Conclusions}

Since bioremediation of harmful substances such as sulfosulfuron from the environment is a prerequisite to maintain the environmental inertia, we identified and characterized two microbial strains, i.e., B. borstelensis and $S$. albogriseolus which have the capability of effectively degrading sulfosulfuron within 10-20 h of growth although no synergistic effect was observed in the microbial consortia form. LCMS-MS analysis further detected aminopyrimidine and a rearranged amine as metabolites in 12 and $20 \mathrm{~h}$ of the microbial growth. However, the potential of these microbial strains to degrade sulfosulfuron needs to be further investigated at the genomic level to understand the effectivity of these strains as bioremediation agents.

Acknowledgements Our sincere gratitude goes to Punjab Biotechnology Incubator, Mohali, for LC-MS analysis of samples and Department of Biotechnology, Maharishi Markandeshwar University, Mullana, Ambala, for providing all the requisite facilities for the said work.

\section{Compliance with ethical standards}

\section{Conflict of interest None.}

Open Access This article is distributed under the terms of the Creative Commons Attribution 4.0 International License (http:// creativecommons.org/licenses/by/4.0/), which permits unrestricted use, distribution, and reproduction in any medium, provided you give appropriate credit to the original author(s) and the source, provide a link to the Creative Commons license, and indicate if changes were made.

\section{References}

Arnold LL, Cano M, John MK, Healy CE, Cohen SM (2001) Effect of sulfosulfuron on the urine and urothelium of male rats. Toxicol Pathol 29(3):344-352
Arya R, Sharma AK (2014a) Screening, isolation and characterization of Brevibacillus borstelensis for the bioremediation of carbendazim. J Environ Sci Sustainability 2(1):12-14

Arya R, Sharma AK (2014b) Bioremediation of carbendazim by Streptomyces albogriseolus. Biointerface Res Appl Chem 4(4):804-807

Arya R, Sharma AK (2016) Biodegradation of carbendazim, a benzimidazole fungicide using Brevibacillus borstelensis and Streptomyces albogriseolus together. Curr Pharm Biotechnol 17(2):185-189

Arya R, Malhotra M, Kumar V, Sharma AK (2015) Biodegradation aspects of carbendazim and Sulfosulfuron: trends scope and relevance. Curr Med Chem 22(9):1147-1155

Bahrampor T, Ziveh PS (2013) Effects of residue sulfonylurea herbicides on wheat. Int J Agro Plant Produc 4(10):2707-2713

Bossi R, Vejrup K, Jacobsen CS (1999) Determination of sulfonylurea degradation products in soil by liquid chromatographyultraviolet detection followed by confirmatory liquid chromatography-tandem mass spectrometry. J Chromatogr 855:575-582

Brar AP, Punia SS, Yadav A, Malik RK (2006a) Effect of pH on degradation of sulfosulfuron in soil. Ind $\mathrm{J}$ Weed Sci 38(1\&2):115-118

Brar PA, Ponia SS, Yadav A, Malik RK (2006b) Microbial degradation of sulfosulfuron in soil under laboratory conditions. Ind J Weed Sci 38(3-4):255-257

Brown HM (1990) Mode of action, crop selectivity, and soil relations of the sulfonylurea herbicides. Pestic Sci 29:263-281

Chhonkar RS, Malik RK (2002) Isoproturon resistance in Phalaris minor and its response to alternate herbicides. Weed Technol 16:116-123

Chhonkar RS, Sharma RK, Chauhan DS, Mongia AD (2006) Evaluation of herbicides against Phalaris minor in wheat in north-western Indian plains. Weed Res 46(1):40-49

Fenoll J, Hellin P, Flores P, Martinez CM, Navarro S (2012) Photpcatalytic degradation of five sulfonylurea herbicides in aqueous semiconductor suspensions under natural sunlight. Chemosphere 87(8):954-961

Hadizadeh MH (2010) Bioassay study of sulfosulfuron herbicide. In: Proceedings of 3rd Iranian Weed Sciences Congress, vol 2, pp 523-526

Kaur SM, Walia US, Randhawa SK (2010) Residues of sulfosulfuron, mesosulfuron+iodosulfuron and pinoxaden in soil, wheat and successive crops. Ind J Weed Sci 42(1, 2):1-8

Loganayagi C, Ramesh A (2013) Mobility of sulfosulfuron and its metabolite aminopyrimidine in soil under lab conditions. J Ecol Environ Sci 2(1):47-54

Malik RK and Singh S (1993) Evolving strategies for herbicide use in wheat: resistance and integrated weed management. In: Proceedings of International Symposium on Integrated weed Management for Sustainable Agriculture 18-20 Nov 1993, pp 225-238

Menne HJ, Berger BM (2001) Influence of straw management, nitrogen fertilization and dosage rates on the dissipation of five sulfonylureas in soil. Weed Res 41:229-453

Ramesh A, Sathiyanarayanan S, Chandran L (2007) Dissipation of sulfosulfuron in water-bioaccumulation of residues in fish- LCMS/MS-ESI identification and quantification of metabolites. Chemosphere 68(3):495-500

Saha S, Kulshrestha G (2002) Degradation of sulfosulfuron, a sulfonylurea herbicide, as influenced by abiotic factors. J Agric Food Chem 50(16):4572-4575

Saha S, Singh SB, Kulshrestha G (2003) High performance liquid chromatography method for residue determination of sulfosulfuron. J Enviro Sci Health B 38(3):337-347

Sarmah AK, Sabadie J (2002) Hydrolysis of sulfonylurea herbicides in soils and aqueous solutions: a review. J Agric Food Chem 50(22):6253-6265 
Sondhia S (2008) Persistence and leaching of sulfosulfuron in wheat (Triticum aestivum). Ind J Agri Sci 79(6):484-487

Sondhia S, Singhai B (2008) Persistence of sulfosulfuron under wheat cropping system. Bull Environ Contam Toxicol 80(5):423-427

Walia US, Brar LS, Dhaliwal BK (1997) Resistance to isoproturon in Phalaris minor ritz. in Punjab. Plant Prot Quart 12:138-140

Walia US, Kaur R, Kler DS (2000) Determining residual effects of new herbicides applied to control Phalaris minor from wheat on the succeeding crops through bioassay. Environ Ecol 18(1):130-133

Yan C, Zhang B, Liu W, Feng F, Zhao Y, Du H (2011) Rapid determination of sixteen sulfonylurea herbicides in surface water by solid phase extraction cleanup and ultra-high-pressure liquid chromatography coupled with tandem mass spectrometry. J Chromatogr B Analyt Technol Biomed Life Sci 879(30):3484-3489 